\title{
ASSOCIATION BETWEEN ANTENATAL CARE AND LABOR COMPLICATION IN MEDAN, NORTH SUMATERA
}

\author{
Dwi Ris Hasanah S., Asfriyati, Fazidah Aguslina Siregar \\ Masters Program in Public Health, Universitas Sumatera Utara
}

\begin{abstract}
Background: The health of future generations is to a great extent determined by the baby's growth and development within the womb. Most problems at birth are caused by prematurity, fetal growth restriction, congenital abnormalities, or asphyxia. With access to antenatal care, especially in early pregnancy, many of these can be prevented or anticipated. This study aimed to determine the association between completeness of antenatal care visit and labor complication in Medan, North Sumatera.

Subjects and Method: A cross-sectional study was conducted at puskesmas (Community Health Center), Medan, North Sumatera. A sample of 133 postpartum women was selected for this study. The dependent variable was labor complication. The independent variable was completeness of antenatal care visit. The data were collected by questionnaire and analyzed by chi-square with Odd Ratio (OR) as measure of association.
\end{abstract}

Results: As much as $65.4 \%$ of the post-partum women under study used antenatal care completely and $44.4 \%$ had labor complication. The risk of labor complication decreased with complete antenatal care visit $(\mathrm{OR}=0.30 ; 95 \% \mathrm{CI}=0.44$ to $0.12 ; \mathrm{p}=0.001$ ).

Conclusion: The risk of labor complication decreases with complete antenatal care visit.

Keywords: antenatal care,labor complication

\section{Correspondence:}

Dwi Ris Hasanah. Masters Program in Public Health, Universitas Sumatera Utara, Medan, North Sumatera. Email: dwiris24@gmail.com.

Mobile: 081397344587

The 4th International Conference on Public Health 